\title{
Journal Clubs in Endocrine Surgery
}

\author{
${ }^{1}$ Mayilvaganan Sabaretnam, ${ }^{2}$ Navneet Tripati, ${ }^{3}$ Naval Bansal, ${ }^{4}$ Roma Pradhan, ${ }^{5}$ Amit Agarwal
}

\begin{abstract}
Journal clubs are a medium to educate clinicians about the process of evidence based medicine. They are effective strategy to keep endocrine surgeons up to date with relevant literature. However, this exercise needs considerable expertise ,skill and dedication on the part of both the presenter and moderator to make it a successful one. We have addressed the methodology for an effective journal club.
\end{abstract}

Keywords: Journal club, Endocrine surgery, Articles.

How to cite this article: Sabaretnam M, Tripati N, Bansal N, Pradhan R, Agarwal A. Journal Clubs in Endocrine Surgery. World J Endoc Surg 2014;6(3):123-126.

\section{Source of support: Nil}

Conflict of interest: None

\section{INTRODUCTION}

The first recorded journal club was that in 1875 by Sir William Osler at McGill University. From then on journal clubs have always played a critical role in medical education. American Medical Association defines journal club is a certified live activity structured around the discussion of a journal article that do not have certified as journal based CME. Generally physicians will read the article prior to the act and discuss the article during the journal club meeting. ${ }^{1-9}$

It is an organized meeting where professionals debate and reflect on the relative merits of scientific articles. It serves as a teaching tool for educators with particular emphasis on how to do research, how to write up and evaluating experience about the topic. ${ }^{1-9}$ In the present day, online journal clubs are also in vogue. ${ }^{4}$

\section{IMPORTANCE OF JOURNAL CLUB ${ }^{3}$}

1. Disseminate knowledge and information.

2. Contribute to evidence based practice.

\footnotetext{
${ }^{1}$ Assistant Professor, ${ }^{2-4}$ Senior Resident, ${ }^{5}$ Professor

${ }^{1-5}$ Department of Endocrine Surgery, Sanjay Gandhi Postgraduate Institute of Medical Sciences, Lucknow, Uttar Pradesh, India

Corresponding Author: Mayilvaganan Sabaretnam, Assistant Professor, Department of Endocrine Surgery, Sanjay Gandhi Postgraduate Institute of Medical Sciences, Raebareli Road Lucknow, Uttar Pradesh, India, Phone: +91-052224954409 2668777, e-mail: drretnam@gmail.com
}

3. To enable hone skills related to oral and written presentation.

4. To develop self confidence to express opinions professionally.

5. A social networking opportunity.

6. Gaining familiarity with basic statistical methods.

7. To conduct structured critical appraisal.

8. Gain insight into a specific clinical problem.

9. To recognize and understand basic study design.

\section{ORGANIZATION OF JOURNAL CLUB ${ }^{1,2,4-9}$}

- Before the journal club

- Identification of a moderator and a presenter

- Finding an article

- Initial reading and review

- Detailed critique-discussion

- Communication with other participants.

- At the journal club

- Presentation format

- Summary of cross-references

- Critique and discussion

- Evaluation.

- After the journal club

- After thoughts

- Appraise the participants

- Letter to editor.

\section{BEFORE THE JOURNAL CLUB}

1. Identification of a moderator and a presenter: Moderator or mentor is a leader who is willing and committed to organize the journal club. He selects and approves the journal article from a group of articles selected by the presenter. This is done usually 1 to 2 months prior to the scheduled presentation. The presenter is the main person in the theme of journal club. The presenter selects a group of articles, in discussion with the moderator and after selection of the article; he/ she ensures that the article is distributed to the other residents and faculty at least 2 weeks prior to the date of presentation. ${ }^{1,2,4-9}$

2. Finding an article: The article ideally should be from a peer reviewed indexed journal published within 6 months from of the date of journal club. The presenter should pick at least 3 to 5 supporting article to go with the primary article. Supporting articles might include up to date reviews, classic articles or land mark 
articles that support or refute the results of primary article. It is the presenter's opportunity to learn how to impact scholarly analysis of a published article of a treatment modality, a prognostic or a diagnostic test. It is therefore better to use population intervention comparator outcome (PICO) method in assessing the article for journal club. ${ }^{1,2,-9}$

Many clinical or research questions can be divided into the following four components:

- P: Population/patient

- I: Intervention/indicator

- C: Comparator/control

- O: Outcome

Common search engines like PubMed, Google Scholar can be used. Hospital or university library can provide recent literature. Nowadays e-libraries and digital libraries are a reality and provide articles at presenter's convenience.

3. Initial reading and review: During the initial reading and review, the presenter should assess whether the subject is interesting to the audience, relevant to practice and it can be sustainable for a meaningful discussion or whether it is controversial. Then he/ she should analyse the structure of the article and also analyse the type of study design, whether it can be followed in the existing setup or whether it make any meaning in the existing treatment modality. ${ }^{1,2,4-9}$

4. Detailed critique: The presenter should make an effort to read the article all the way thoroughly and also the key references. He should use a structured list to assist his review and it should be always a balanced approach. ${ }^{1,2,4-9}$

He should be clear about the study design and the bias if any in the study. The following questions should be addressed:

- Issues addressed by the article: what is the research question? Why does it matter? How does it fit in already known literature? Whether can it help solve important problems for practice or policy?

- Design of the study : Is the design appropriate for the question?

- Study methods : How participants were selected?

: How key variables defined and measured?

: Confounding factor

: How information was interpreted?

- Main findings : Whether this study advances current knowledge?

- Generalizability?

- Implication

: How information can be used to change practice, policy or training?
5. Enriching discussion: To have a good discussion, the presenter should review local practices, should compare and contrast with other article. $\mathrm{He} /$ she can contact other similar expert centers. They can engage experts like local topic experts or guest speakers.

6. Communication with other participants: Time frame for communication with other participants should be at least 1 to 2 weeks before presentation. Hard copy or soft copy should be made available. A word about copy right law should be borne in mind. For example, with Science Direct/Elsevier policy.

'Permit authorized users to transit an article, by e-mail in print to colleagues for the purpose of scholarly study ...'

\section{AT THE JOURNAL CLUB}

7. Presentation format: Power point or word can be used. thirty minutes shall be the ideal time:

- Topic back ground -3 to 5 minutes

- Hypothetical case or real case - 2 to 3 minutes

- Paper presentation including Figures and Tables 10 to 15 minutes

- Critical appraisal -7 to 10 minutes

- Summary or summing up -5 minutes.

The presenter should aim to complete his presentation within the allotted time and there should be sufficient time for a few questions from the attendees. He should not consume excess time or get too over involved in one aspect of the article.

8. Summary of relevant references and discussion: All relevant literature supporting and also antagonizing the article should be summarized Tables can be used as effective tool to incorporate large data and ease the discussion. Sufficient time should be devoted for discussion.

9. Evaluation: The presentation should be evaluated by the moderator at the end using validated format (Fig. 1). The presenter should be aware of the format and prepare his presentation to cater that format. Once presenters are in the 3rd year of training, they can also self evaluate the presentation which shall be of use when they themselves become moderators.

\section{AFTER THE JOURNAL CLUB}

10. After thoughts: The presenter can recollect the main areas of discussion and also the issues which needed further reading. Certain areas may require further literary search and input from other specialties.

11. Appraise the participants: New literature or articles which support or refute can be apprised to the other participants. If much literature is available then question and answer format can help in appraising. 


\section{Journal club presentation evaluation form}

Student name:

Date:

Journal article:

Evaluator:

5: Excellent or exceptional

4: Very good

3: Acceptable or good

2: Good

1: Unacceptable

1. Presentation of the clinical trial Explains:

- Study goal

- Methodology

- Results

2. Review of the pertinent primary literature 5

- Identifies other recent clinical trials of the same drug/procedure

- Primary literature is condensed by collating similar data (tables and graphs may be used)

- Primary literature data are correctly summarized

- Student elaborates on any major attributes or deficiencies of these data. If none are present, this is stated
3. Evaluation of the clinical trial being presented
$54 \quad 3$
21

- Identifies strengths and weaknesses of the methodology and/or conduct of the trial

- Assesses and critiques the statistical analysis

- Draws own conclusions and contrasts them with authors(s)

- Student's own conclusions about the trial are correct
4. Ability to answer questions 5
4 3
2

- Answers are logically presented

- Answers are accurate

- Student can think on his/her feet-may theorize, if unsure of answer, but indicates such

5. Delivery of presentation $\begin{array}{lllll}5 & 4 & 3 & 2 & 1\end{array}$

- Organization and preparedness

- Is well-prepared (does not reread article)

- Introduces presentation (tells them what she/he is going to tell them) and summarizes

- Presentation (tells them what she/he told them)

- Presentation and communication skills confidence are apparent $\begin{array}{llllll}5 & 4 & 3 & 2 & 1\end{array}$

- Direct eye contact

- Proper rate of speech

- Appropriate pitch of voice

- Absence of obvious nervousness (trembling voice; restless movements)

- Professional phraseology

- Fluent speech

- Smooth delivery

- Appropriate use of pauses

Printed and audiovisual materials are accurate, clear and effective (complement what is verbally presented) Comments (may be continued on back of form)

Evaluator's signature

Date

Fig. 1: Journal club evaluation form

12. Letter-to-editor: Final step of a successful journal club can result in a letter to editor if the presenter and moderator feel the points of discussion are note-worthy and shall be helpful for future readers of the article and can contribute further research or change in practices.

\section{JOURNAL CLUB IN ENDOCRINE SURGERY}

Since, endocrine surgery is a newer specialty, there are few journals which are dedicated only to endocrine surgery like world journal of endocrine surgery. However, presenter can get articles from world journal of surgery 


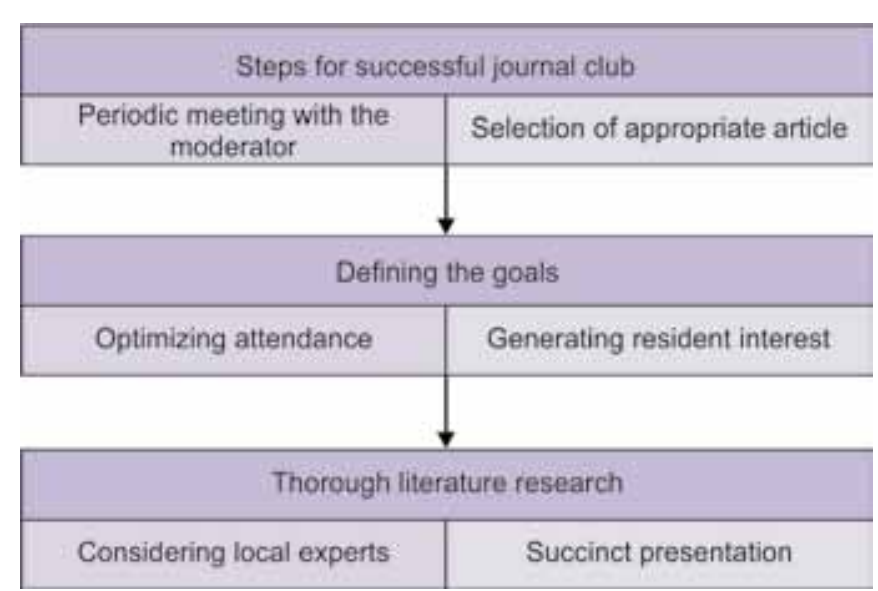

Fig. 2: Steps for a successful journal club

(official Journal of International Surgical Society), surgery (official Journal of American Association of Endocrine Surgeons) and world journal of endocrine surgery (official Journal of Asian Association of Endocrine Surgeons, and also certain endocrinology journals like journal of clinical endocrinology and metabolism, clinical endocrinology and others.

\section{CONCLUSION}

Even though journal club is a daunting assignment for many trainees in their carriers, this academic exercise improves clinical knowledge, initiates additional reading and also, improves examination scores. ${ }^{1,2}$ So, the pre- senter should make full use of the limited opportunities of presentation to hone their skills and make their journal presentation a successful one (Fig. 2).

\section{REFERENCES}

1. Judd S, Antaki F. Approach to presenting a clinical journal club. Gastroenterology 2014 Jun;146(7):1591-1593.

2. Shifflette V, Mitchell C, Mangram A, Dunn E. Current approaches to journal club by general surgery programs within the Southwestern surgical congress. J Surg Educ 2012 MarApr;69(2):162-166.

3. Lee AG, Boldt HC, Golnik KC, Arnold AC, Oetting TA, Beaver HA, Olson RJ, Carter K. Using the journal club to teach and assess competence in practice-based learning and improvement: a literature review and recommendation for implementation. Surv Ophthalmol 2005 Nov-Dec;50(6):542-548.

4. Lizarondo L, Kumar S, Grimmer-Somers K. Online journal clubs: an innovative approach to achieving evidence-based practice. J Allied Health Spring 2010;39(1):e17-22.

5. Millichap JJ, Goldstein JL. Neurology journal club: a new subsection. Neurology 2011 Aug 30;77(9):915-917.

6. Akhund S, Kadir MM. Do community medicine residency trainees learn through journal club? An experience from a developing country. BMC Med Educ 2006 Aug 22;6:43.

7. Valentini RP, Daniels SR. The journal club. Postgrad Med J. 1997 Feb;73(856):81-85.

8. Stapleton JJ. The successful journal club. Clin Pediatr Med Surg 2007 Jan;24(1):51-55.

9. Greene WB. The role of journal clubs in orthopaedic surgery residency programs. Clin Orthop Relat Res 2001 Jun;155(6): 639-640. 